\title{
A ESCRITA DE DIÁRIOS NA FORMAÇÃO DOCENTE
}

\author{
Ana Paula Gestoso de Souza* \\ Reginaldo Fernando Carneiro** \\ Silvia Maria Perez ** \\ Evaldo Ribeiro Oliveira****
} Aline Maria de Medeiros Rodrigues Reali**** Rosa Maria Moraes Anunciato de Oliveira*****

RESUMO: Este artigo buscou investigar as contribuições da escrita de diários para estudantes de um curso de Pedagogia que já haviam cursado as disciplinas de estágio supervisionado para a docência, em que uma das atividades se referia à elaboração de diários de campo. Os dados foram coletados por meio de questionários com perguntas abertas. A análise dos dados evidenciou que os alunos registravam os acontecimentos no diário logo após o estágio e realizavam uma descrição detalhada deles. Para a maioria dos estudantes a escrita dos diários possibilitou a reflexão sobre a prática observada e sobre a sua própria prática, configurou-se como um apoio à memória e possibilitou o distanciamento das experiências vividas, permitindo a análise mais densa destas. Além disso, evidenciou-se a importância de o formador oferecer feedbacks, orais ou escritos, e de a reflexão sobre os acontecimentos ser pautada no referencial teórico.

Palavras-chave: Formação de Professores. Diário de Campo. Aprendizagem da Docência.

\footnotetext{
* Mestre e Doutoranda em Educação pela Universidade Federal de São Carlos; Professora da rede de ensino do Estado de São Paulo e supervisora da tutoria virtual do curso de Pedagogia da Universidade Federal de São Carlos (UFSCar). E-mail: ana.gestoso@gmail.com

* * Mestre e Doutorando em Educação pela Universidade Federal de São Carlos (UFSCar); Tutor virtual do curso de Pedagogia da Universidade Federal de São Carlos (UFSCar). E-mail: reginaldo_carneiro@yahoo.com.br

** Mestre em Ciências da Computação e Doutoranda em Educação pela Universidade Federal de São Carlos (UFSCar); Analista de TI e tutora virtual do curso de Pedagogia da Universidade Federal de São Carlos (UFSCar). E-mail: silvia@power.ufscar.br

**** Mestre e Doutorando em Educação pela Universidade Federal de São Carlos (USFSCar); Membro do Núcleo de Estudos Afro-Brasileiro da Universidade Federal de São Carlso (UFSCar). E-mail: evaldoneab@yahoo.com.br

**** Doutora em Psicologia Experimental; Professora do Departamento de Teorias e Práticas Pedagógicas e da PósGraduação em Educação da Universidade Federal de São Carlos (UFSCar). E-mail: darr@ufscar.br

***** Doutora em Educação; Professora do Departamento de Teorias e Práticas Pedagógicas e da Pós-Graduação em Educação da Universidade Federal de São Carlos (UFSCar). E-mail: rosa@ufscar.br
} 


\section{THE WRITING OF DIARIES IN TEACHER EDUCATION}

ABSTRACT: This article investigated the contribution that keeping a diary, made to pedagogy students who had already attended a course with a supervised teaching stage, in which one of the activities involved the development of field diaries. Data was collected from questionnaires with open questions. Data analysis showed that the students recorded the events in the diary shortly after the supervised lesson/teaching period and that they produced a detailed description of the facts/events. For most students, keeping a diary allowed them to reflect on the practice (of other students) they observed, and on their own practice, while also assisting their memory of events and permitting some detachment from their experiences, thereby allowing a more profound analysis of what took place. Moreover, it provided evidence of the importance of the supervisor offering feedback, written or oral, and also the importance of referring to theoretical literature while reflecting on one's teaching.

Keywords: Teacher Education; Field Daily; Teacher's Learning.

\section{Introdução}

Neste artigo, discutimos as contribuições da escrita de diários para a aprendizagem da docência de futuros pedagogos. Apoiados em Zabalza (1994), Yinger e Clark (1981), Souza e Cordeiro (2007), Galiazzi e Lindemann (2003), Silva e Duarte (2001), entre outros, buscamos compreender e caracterizar o desenvolvimento profissional de estudantes de pedagogia em formação por meio dos diários elaborados durante a prática do estágio.

Os participantes da pesquisa foram nove estudantes de um curso de Pedagogia - um homem e oito mulheres - que já haviam cursado as disciplinas de estágio supervisionado para a docência. Devido ao fato de a maioria das participantes serem mulheres, optamos por utilizar no texto o gênero feminino. Para realizar o trabalho, as estudantes responderam a um questionário com questões abertas cujo intuito era verificar quais seriam, sob a sua ótica, as contribuições da escrita de diários para a sua formação, qual o processo percorrido e sua caracterização na elaboração dos diários.

Nessa perspectiva, consideramos que esta pesquisa pode dar pistas sobre as maneiras como se desenvolve o processo de aprendizagem dos futuros professores, ao elaborarem diários no decorrer do estágio; pode, também, elencar alguns elementos da formação inicial que proporcionam o desenvolvimento docente. 
No presente texto, inicialmente, traremos os aportes teóricos sobre a formação do professor e também sobre as potencialidades da escrita de diários. Faremos, ainda, uma breve descrição das estratégias metodológicas que, em razão da natureza qualitativa da pesquisa, permitiram investigar essa temática. Por fim, apresentaremos os dados, as análises e os resultados que nos possibilitaram compreender as características do processo de elaboração do diário, assim como as contribuições e as implicações para a formação docente.

\section{Formação do professor e a escrita de diários}

Compreendemos a aprendizagem da docência na perspectiva de desenvolvimento profissional, ou seja, como um processo pessoal, permanente, contínuo e inconcluso. De acordo com Mizukami et al. (2003, p. 16),

A ideia de processo - e portanto, de continum - obriga a considerar a necessidade de estabelecimento de um fio condutor que vá produzindo os sentidos e explicitando os significados ao longo de toda a vida do professor, garantindo, ao mesmo tempo, os nexos entre a formação inicial, a continuada e as experiências vividas.

A atividade docente exige diversas necessidades formativas como: dominar o conhecimento a ser ensinado e saber ensiná-lo de formas diferentes; saber gerenciar uma sala de aula; compreender os condicionantes da prática educativa que vão além das atitudes docentes; entender e saber lidar com a complexidade do cotidiano escolar; conhecer o aluno, suas necessidades de aprendizagem, seu contexto e sua família; não ficar alheio às mudanças socioeconômicas, às políticas públicas e aos avanços tecnológicos, aspectos que influenciam diretamente ou indiretamente a prática educativa. Assim sendo, a carreira docente exige uma formação, conhecimentos, competências e técnicas específicos que são apropriados e construídos na formação inicial e continuada e na experiência profissional, sendo que a atuação docente se modifica ao longo da carreira. Considerando essas premissas, também ressaltamos que a escrita de diários pode ser um dos instrumentos de aprendizagem da docência. 
Especificamente sobre a importância do ato de escrever, destacamos as ideias de Catani et al., que fazem referência a Albert (1993 apud CATANI, 2000, p. 41-42) e apontam que:

A escrita supõe um processo de expressão e de objetivação do pensamento que explica sua atitude de reforçar ou constituir a consciência daquele que escreve. Escrever sobre si é auto-revelar-se, é um recurso privilegiado de tomada de consciência de si mesmo, pois permite "atingir um grau de elaboração lógica e de reflexibilidade", de forma mais acabada do que na expressão oral. A autobiografia é um dos elementos que compõem um conjunto diversificado de produções sobre si representando uma das "mais nobres qualidades da escritura identitária".

Desse modo, segundo Catani et al. (2000), busca-se compreender mais profundamente as relações que os indivíduos mantêm com o conhecimento e a forma como atribuem significados ao que vivenciam na escola.

Mizukami et al. (2003) também assinala a potencialidade da escrita para o processo formativo da docência, pois ela proporciona a análise sistemática, a organização do pensamento, o retomar as vivências, enfim, permite pensar sobre e compreender a própria prática.

De acordo com Zabalza (1994), ao escrever sobre sua prática, o professor aprende e (re)constrói seus saberes. $\mathrm{O}$ autor afirma que os diários permitem focar as análises nos fatos ocorridos a partir da integração das dimensões referencial e expressiva. Considerando essa colocação, é necessário destacar nossa compreensão sobre o conceito de fato e de acontecimento. Sendo que para Malerba (2002, p. 119) as distinções entre fatos e acontecimentos "são mais sutis do que se possa pensar a primeira vista".

De acordo com Langlois e Seignobos (apud MALERBA, 2002, p. 135), podemos considerar três categorias de fatos: “1) seres vivos e objetos materiais; 2) os atos dos homens (individuais e coletivos); 3) os motivos e concepções (o que moveria os homens a agir, causalidade)". Malerba (2002, p. 135) aponta que os acontecimentos, que são únicos e singulares, inserem-se na categoria dos fatos humanos. Sendo assim, neste artigo, consideramos o acontecimento como sinônimo de fato humano, sendo que este tem o homem como ator.

Na concepção de Veyne (apud MALERBA, 2002, p. 129), “os fatos, pequenos ou grandes, visíveis ou não aos que os experimentaram, 
existem em si mesmos, ocultos na floresta densa do cotidiano ou nas profundezas obscuras da longa duração". A dificuldade do historiador está em identificar a significância entre um conjunto de fatos, ou seja, ele escolhe determinados aspectos e refuta outros, ordena os fatos e assim constitui uma narrativa.

Traçando um paralelo entre as contribuições desse debate na historiografia e a compreensão do processo de desenvolvimento profissional de professores, vemos que, nessa perspectiva, o sujeito em formação é quem atribui significância maior ou menor a um fato observado ou a uma experiência vivida, tendo em vista seu processo de reflexão sobre esse acontecimento e os possíveis liames entre ele e outros fatos ou acontecimentos observados, experimentados por ele ou pelos estudos teóricos realizados. Assim, não importa o caráter de verdade ou as provas de sua ocorrência tal como é narrado no diário, mas a reflexão que se faz sobre o assunto é que define o quanto está sendo formadora a experiência.

Esses escritos constituem-se pela expressão e pela elaboração do pensamento e dos dilemas dos docentes. Desse modo, aqueles que escrevem diários podem tornar-se investigadores de si próprios e, consequentemente, da prática que desenvolvem na escola.

Zabalza (1994) destaca quatro aspectos do diário que dão a esse tipo de documento uma potencialidade expressiva: exige o registro escrito, implica reflexão, integra o expressivo e o referencial, possui caráter histórico e longitudinal.

Com relação ao primeiro aspecto, para Yinger e Clark (1981), as pessoas aprendem escrevendo, pois, ao escrever, é preciso recriar as experiências vividas, e isso envolve emoções e intuições e também a organização dessas experiências em uma mensagem estruturada. Além disso, escrever refere-se a um processo de criação-revisão, pois, ao ler o que escreveu, é possível ao autor avaliar esse registro, considerando se a escrita está clara e refletindo sobre seus objetivos. Segundo os autores, essa escrita não acontece de modo mecânico e inconsciente, pois aquele que escreve estabelece conexões entre o que já conhece e a nova informação. Por fim, Yinger e Clark (1981) afirmam que a escrita é pessoal e ativa. Pessoal, pois é o autor quem seleciona as informações apresentadas, os fatos narrados e também decide a forma de apresentação do relato; e ativa porque se refere a um processo que envolve estruturação, organização, releitura, reflexão e modificação do texto. 
Considerando esses pressupostos, Zabalza (1994, p. 95) afirma:

Ao narrar a sua experiência recente, o professor não só a constrói linguisticamente, como também a reconstrói ao nível do discurso prático e da actividade profissional (a descrição vê-se continuamente excedida por abordagens reflexivas sobre os porquês e as estruturas de racionalidade e justificação que fundamentam os factos narrados).

Em outras palavras, para o autor, a narração implica reflexão, pois, ao escrever, é possível distanciar-se e analisar as experiências relatadas a partir de outra perspectiva, permitindo o diálogo consigo mesmo.

Segundo Zabalza (1994), esse processo de reflexão pode incidir sobre duas vertentes: referencial e expressiva. Assim sendo, a reflexão pode referir-se ao objeto narrado (por exemplo, a condução da aula, o comportamento dos alunos) e ao narrador, ou seja, o próprio professor (por exemplo, suas ações docentes, seus conhecimentos, seus sentimentos, suas emoções). $\mathrm{O}$ autor destaca que em alguns diários uma vertente pode prevalecer, em detrimento da outra; em outros, pode haver casos mistos. Percebe-se que o caráter pessoal do diário é multidimensional e refere-se ao registro dos saberes, dos sentimentos, das ações, das tomadas de decisões do professor; remete também ao próprio sentido do diário: esse documento tem sentido pleno para o seu autor, que também é destinatário do relato.

O quarto aspecto levantado por Zabalza (1994) é que, como o diário "vai estabelecendo a sequência dos fatos a partir da proximidade dos próprios fatos" (p. 96), é longitudinal e histórico, o que permite observar a evolução dos acontecimentos; a forma como eles ocorrem; os condicionantes que estão intrínsecos; as mudanças que perpassam esses acontecimentos, etc. Além disso, a sequência linear temporal com que os fatos são relatados evita a homogeneidade de perspectiva sobre os acontecimentos, isto é, o professor escreve os acontecimentos em determinado dia e não retorna a escrever até um próximo momento; por isso, cada dia relatado envolve determinada perspectiva sobre os acontecimentos, o que não ocorre, por exemplo, em uma escrita autobiográfica produzida num período narrativo unitário, pois a perspectiva do momento em que essa escrita foi elaborada influencia os fatos passados.

A partir dessas considerações, verifica-se que as potencialidades formativas da escrita de diários só são possíveis se eles não se organiza- 
rem somente por descrições e relatos de experiências vividas. É fundamental que o diário também contemple a análise dos acontecimentos, o registro das reflexões sobre as vivências e os caminhos a serem traçados para lidar com os dilemas docentes.

Diversos estudos mostram as potencialidades formativas da escrita de diários. Silva e Duarte (2001) investigaram as potencialidades formativas da escrita de diários de aula por licenciandos do curso de Biologia, para tanto analisaram o discurso utilizado por onze professores em formação, divididos em três grupos, ao elaborarem os diários no decorrer do estágio, baseando-se nas seguintes categorias de discurso: discurso fatual não reflexivo, discurso prudencial, fatual reflexivo (explicativo/hipotético), discurso justificativo e discurso crítico.

Considerando o discurso não reflexivo nos três grupos, o fatual foi o mais utilizado, sendo que a maioria dos registros engloba os acontecimentos educativos experienciados pelos estagiários, alguns se referiram ao relato das preocupações diante de um acontecimento, outros à avaliação de sua atuação ou à dos estudantes.

Considerando o discurso reflexivo, o fatual-explicativo/hipotético e justificativo foi o mais utilizado pelos futuros professores. Nesses casos, a maior preocupação era justificar o uso de determinadas estratégias de ensino e formas de atuação, registrar a utilidade do planejamento, explicar a ocorrência de alguns acontecimentos e suas consequências, bem como registrar seus sentimentos diante das experiências vividas.

Os autores verificaram que os professores em formação de um dos grupos elaboraram registros mais reflexivos, pois, neste, o estágio foi permeado por uma metodologia de formação reflexiva. Este:

Foi o único grupo do estudo onde os professores estagiários utilizaram discurso reflexivo numa percentagem superior à de discurso não-reflexivo. Foram estes professores estagiários os que revelaram um maior equilíbrio entre a utilização do discurso que incidiu na descrição e fornecimento de informações (discurso factual) e o que estabeleceu/identificou as relações que, na sua perspectiva, tinham motivado a ocorrência de muitos dos acontecimentos que experienciaram (discurso explicativo/hipotético); bem como foi o grupo que com mais frequência justificou o porquê da adopção de determinadas atitudes e estabeleceu formas alternativas de acção (discurso justificativo) (SILVA e DUARTE, 2001, p. 83). 
Sendo assim, validam a ideia de que a escrita de diários pode possibilitar a análise mais aprofundada das experiências vividas no decorrer do estágio, contudo, concluem que a análise é potencializada quando o estágio é composto por atividades que permitem a reflexão, além do diário de aula.

Outro estudo que podemos destacar é Souza e Cordeiro (2007), que enfatizam que a escrita de diário exige tempo para parar e refletir. Isso gerará dúvidas que afetam e são afetadas pela prática docente. Para esses autores (2007, p. 46), a "produção e socialização das escritas de si e os processos de formação de professores e leitores se modelam entre as experiências que marcam as histórias de vida de cada sujeito e seus singulares percursos de formação e autoformação". Assim, podemos pensar em uma estreita inter-relação que não pode dissociar as histórias de vida do professor e sua formação profissional. O registro em diário possibilita o "redescobrir caminhos percorridos, cenários e fatos vivenciados por uma determinada pessoa em diferentes tempos e espaços, encaminhando-a a uma reflexão sobre a própria atuação" (SOUZA; CORDEIRO, 2007, p. 46).

Dessa forma, o diário é atemporal porque permite que, a partir de uma análise mais profunda ou, ainda, após um tempo de distanciamento dos acontecimentos, redescobrir caminhos que poderiam não ser perceptíveis para seu autor em um primeiro momento. Assim, a prática docente pode ser reexaminada de outro ponto de vista, sendo possível provocar mudanças em sua atuação em sala de aula. Além disso, a escrita dos diários explicita o esforço de cada indivíduo em colocar no papel seus conhecimentos, valores, desejos, concepções, crenças e, assim, de acordo com os autores (p. 46), "ir construindo a sua identidade, num diálogo contínuo com seus contextos".

Por fim, os diários permitem rever práticas docentes cristalizadas porque os professores, ao lembrarem e ao escreverem, reconstroem suas experiências de sala de aula, refletindo sobre seu percurso, o que pode proporcionar a compreensão dessas práticas. Isto é, a escrita do diário, na perspectiva de Souza e Cordeiro (2007, p. 47), "possibilita analisar a prática pedagógica, visto que instaura um rememorar sobre o cotidiano em sala de aula, aprimorando aspectos relacionais e didáticos vinculados ao trabalho docente".

A investigação de Medeiros e Pátaro (2009) teve como objetivo discutir a importância da escrita na formação inicial de professores, a par- 
tir dos registros em diários, focando as práticas desenvolvidas no estágio supervisionado de um curso de Pedagogia. De acordo com as autoras (2009), o estudo evidenciou que os diários dão forma às impressões imediatas dos estudantes, além de possibilitar a reflexão, que pode provocar transformações da ação docente e da própria realidade escolar.

Os registros permitiram que os licenciandos buscassem compreender a relação entre a teoria estudada no curso e a prática, podendo observar as contradições existentes. Dessa forma, puderam buscar novos conhecimentos e compreensões, o que foi potencializado pelo processo de escrita. Essa prática de reflexão sobre as experiências durante o estágio pode contribuir para sua formação e também para a construção da identidade do futuro professor. Segundo as autoras (2009, p. 9), a escrita faz parte de um processo que busca "a formação consciente e crítica de futuros/as docentes. Mais do que apenas um momento de reflexão e aprendizagem individual, deve ser encarado como possibilidade de intervenção na realidade educacional e maior articulação entre os cursos de Pedagogia e a Escola Básica".

Alves apresenta os resultados das investigações de M. L. Holly (1992 apud ALVES, 2004), que destaca que, ao escreverem diários, os professores demonstram suas preocupações sobre o ensino, questionam a si próprios e aos contextos de ensino e, desse modo, exploram e investigam o processo de ensino que desenvolvem, tornando-se reflexivos e autocríticos.

Também a pesquisa de Galiazzi e Lindemann (2003) apresenta as potencialidades formativas da elaboração de diários reflexivos. Os autores foram uma estagiária, professores da universidade e da escola na qual o estágio foi desenvolvido. As autoras destacam que o diário configurou-se como um instrumento de diálogo e teve papel importante para a formação tanto da estagiária quanto das professoras formadoras. Além disso, afirma-se que os agentes externos analisarem os registros potencializou os diários como instrumentos de reflexão. Outra potencialidade é que o diário possibilitou a construção de propostas de ensino; o delineamento dos objetivos dessas propostas; o acompanhamento do trabalho desenvolvido pela estagiária, destacando os erros e os acertos; a discussão pedagógica do desenvolvimento dessas propostas e a avaliação destas. Além disso, o diário permitiu o aprofundamento dos questionamentos e das orientações da formadora sobre conhecimentos atitudinais, bem como o desabafo da estagiária. 
Zalbaza (1994) investigou como os diários de aula podem contribuir para o estudo dos dilemas ${ }^{1}$ práticos dos professores, porém, para compreender, efetivamente, e analisar esses dilemas não é suficiente ler os diários dos docentes: é preciso estabelecer mais contato com os professores, o que pode ocorrer por meio de entrevistas e discussões aprofundadas sobre os registros. Segundo o autor, o diário possibilita identificar o pensamento particular dos professores: "Cada diário refere-nos um tipo de realidades distintas e refere-as de maneira diferente. Através dos diários pode-se extrair a 'alma' do pensamento dos professores sobre as suas aulas" (p. 194).

Alves (2004) também afirma que a elaboração de diários possibilita o desenvolvimento pessoal e profissional do docente e permite a investigação dos dilemas deste.

O diário é um instrumento de investigação que nos permite aceder à intimidade dos sujeitos, dos professores em concreto, e, simultaneamente, nos viabiliza o encontro com as suas tensões, as suas perplexidades, contando-se, entre estas, as bipolaridades dilemáticas, a que a profissão nos vai relegando, mas que, reflexivamente, poderemos ultrapassar pelas nossas singulares, mas também mútuas confissões (ALVES, 2004, p. 238).

Os resultados das pesquisas apresentadas evidenciam diversas potencialidades - importantes para a formação do futuro professor - da escrita de diários.

\section{0 caminhar da pesquisa}

Os participantes da pesquisa foram nove alunos do último ano do curso de Pedagogia - um homem e oito mulheres - que haviam cursado o estágio supervisionado para a docência e elaboraram diários de campo. Optamos por utilizar no texto o gênero feminino, pois a maioria das participantes era de mulheres.

Em um primeiro momento, entregamos uma Carta-Convite e um Termo de Consentido Livre e Esclarecido a essas alunas, com o intuito de informá-las sobre os objetivos da pesquisa, identificar quem se interessava em participar e solicitar a autorização para a realização do estudo. Destacamos que os nomes utilizados no artigo são fictícios e foram escolhidos pelas participantes. 
Para a coleta de dados, elaboramos um questionário com questões abertas, com o intuito de apreender, sob a ótica das participantes, quais as contribuições da escrita de diários para a formação dos docentes e as aprendizagens favorecidas. Por isso, solicitamos que as estudantes relatassem e analisassem seu processo de escrita dos diários, que apontassem a influência desse processo na sua formação docente, que explicitassem as contribuições dos feedbacks do supervisor de estágio para seu processo formativo e informassem se utilizariam a escrita de diários como instrumento de formação.

Após uma primeira tabulação dos dados obtidos, elaboramos questionários individuais para cada sujeito, com o objetivo de aprofundar os pontos levantados pelo primeiro questionário.

Consideramos que a investigação desenvolvida contempla a importância da voz das participantes, ou seja, proporciona compreendêlas a partir de suas perspectivas, pois a proposta da pesquisa desenvolvida foi investigar as contribuições da escrita de diários para a formação de futuras professoras, sob a sua própria ótica. Ressaltamos também que os procedimentos metodológicos permitiram a coleta de dados descritivos, e essa descrição foi útil para a melhor compreensão da questão estudada.

Ressaltamos também que não focamos apenas os resultados: privilegiamos o processo de investigação. Além disso, partimos de uma questão inicial ampla, que se delineou melhor no decorrer da investigação, tendo em vista o referencial teórico e os dados coletados.

Considerando as características da pesquisa qualitativa, a organização e a categorização dos dados, em um primeiro momento, foram guiadas por critérios flexíveis e definidos de acordo com o objetivo da investigação, estabelecendo padrões de análise.

Depois disso, essas categorias foram mais bem-definidas, e realizamos uma análise mais profunda dos dados, subsidiada pelo referencial teórico, objetivando a construção de interpretações e explicações que respondessem à questão da pesquisa. Esse processo de análise exigiu várias leituras dos dados, o cruzamento de informações que a princípio pareciam desconexas, a interpretação de respostas, entre outros, além de uma análise rigorosa dos dados, para que a investigação não se limitasse ao relato de experiências. 


\section{0 processo de elaboração do diário}

Sobre o processo de elaboração dos diários vivenciado pelas estudantes, verificamos que cinco alunas afirmaram que os escreviam logo que chegavam em casa, após o estágio, pois assim poderiam evitar esquecer detalhes dos fatos vivenciados. Algumas destacaram que faziam anotações na sala de aula, durante o estágio, nas quais depois se baseavam para elaborar o diário. De acordo com essas alunas, essas estratégias contribuíam para a elaboração de relatos mais detalhados. A seguir, alguns exemplos dessa prática:

Os meus diários eram elaborados após cada dia de estágio, a partir de algumas anotações que eu fazia na escola eu ia relembrando os fatos ocorridos. (Carol)

Os diários foram elaborados o mais próximo possivel das minhas inserções (geralmente no mesmo dia) a fim de contemplar o máximo de informações possiveis, permitindo mais reflexões. (Simone)

Durante as aulas que en assistia na sala em que en faz̨ia o estágio de docência en fazia anotações sobre tudo o que acontecia, em uma sequência de fatos em um texto corrido. (Lara)

É importante destacar que uma das alunas não conseguia fazer o registro logo após o estágio e informou que isso prejudicou a qualidade das descrições e das possíveis reflexões durante a elaboração dos textos.

Amaral, Moreira e Ribeiro (1996) ressaltam a importância de o diário ser elaborado próximo ao tempo de ocorrência dos acontecimentos, pois, desse modo, o autor do texto pode "recordar e reconstruir o contexto, os comportamentos e as ideias, quais peças de um puzzle que ainda se conseguem encaixar corretamente, não deturpando ou truncando a complexidade holística do ato educativo" (p. 106). Além disso, segundo os autores, é preciso estar em um local tranquilo para escrever os diários.

Com relação ao modo de apresentação das informações, sete alunas afirmaram que faziam uma descrição detalhada dos fatos, de acordo com a sequência em que ocorriam. Via de regra, essas alunas relatavam os acontecimentos desde o horário em que chegavam à sala de aula em que desenvolviam o estágio até o momento em que saíam. Os trechos dos discursos de Maria, Lara e Rachel evidenciam esse fato. 
Tentava colocar detalhes que pudessem me fazer refletir sobre aquele momento especifico. (Maria)

A escrita sempre ia do momento em que eu entrava na sala de aula até a hora de levar os alunos para a quadra, quando iam embora. Cada uma das ações da professora ou mesmo dos alunos era relatada para que depois eu pudesse refletir em cima das ações. (Lara)

Realizei a escrita dos acontecimentos observados de uma maneira que melhor pudesse relatar o que realmente ocorria em sala de aula, as interações entre os alunos, entre estes e a professora, enfim, todas as situações. Também discorria nos diários [sobre] minhas interaçôes com as crianças, como quando as auxiliava em algum exercício, em trabalhos em grupo, etc. Os diários foram norteados pelas situações concretas da sala de aula. (Rachel)

Identificamos, além do modo de apresentação das informações nos diários, as formas de análise dos acontecimentos ali descritos. As nove alunas afirmaram que, ao longo do estágio, fizeram reflexões ${ }^{2}$ sobre as experiências vividas, mas nem todas as registravam nos diários.

Isso acontecia com Rachel, cujas reflexões foram escritas no relatório entregue ao final do estágio. Ela aponta que, apesar de não registrar as análises sobre os acontecimentos do estágio, relatava-as para os colegas e para a supervisora de estágio, nos encontros semanais que realizavam na faculdade. Segundo a graduanda, esse diálogo configurou momentos de aprendizagem: "Pude também por meio dos diários relatar à minha turma na disciplina de estágio, experiências, situações concretas da sala de aula, fato que desencadeou discussões teóricas e reflexivas". (Rachel)

Avaliação positiva dessas produções foi feita também por Carol, que destacou ser o processo de escrita um facilitador para as reflexões.

O processo de escrita dos diários facilitava para que eu pudesse recordar o ocorrido e analisar mais cuidadosamente as minhas atividades de estágio, podendo assim, perceber algumas falhas e tentar corrigi-las, além de refletir sobre as práticas ocorridas na escola, sobre o comportamento dos alunos, etc. (Carol)

Ao relatar um dia de estágio no qual Simone havia realizado algumas atividades com as crianças (brincadeira e atividade de escrita de palavras), ela fez a seguinte reflexão:

Pude constatar que as crianças têm bastante interesse em aprender, em ler e escrever, se isto for realizado de uma forma leve e agradável, uma vez que gostaram de brincar de escrever e ler o que falavam e pediram bastante para escreverem em lousa, além de mostrarem-se bem felizes com suas conquistas. (Simone) 
Também a respeito das reflexões, Francisco, apesar de não afirmar categoricamente que as fazia, expõe que "o processo de escrita do diário possibilitava repensar em situações vivenciadas como o diário da regência que possibilitou rever e pensar alguns elementos da mesma". Para ele, a escrita dos diários era o momento de relembrar os acontecimentos vivenciados durante os estágios, mas também um espaço em que podia expor suas angústias.

Um procedimento diferente de registro foi utilizado por Lara. Ela informou que escrevia suas reflexões nos diários e que esse processo era longo. Via de regra, ao chegar em casa após o estágio, relia os diários (que a princípio se configuravam mais como um relato descritivo) e apoiava-se em referenciais teóricos para realizar as reflexões sobre as experiências vividas e registrá-las.

Ao chegar na minha casa, eu relia os diários e comecava a pensar a minha prática e a prática da professora a partir de textos lidos para a disciplina e outras disciplinas que tive durante o curso. [...] Para fazer a reflexão precisava estar com os textos da matéria em dia e depois disso relia os diários de observação e a então começava a escrever a reflexão.

Outra forma de produção foi utilizada por Marília: escrevia "como pensava que a professora deveria agir", também fazia algumas reflexões sobre as atividades propostas, sobre o desempenho dos alunos ao realizarem as atividades e registrava suas perspectivas sobre o ocorrido no dia de estágio.

Analisando a totalidade das participantes, constatamos que, em alguns casos, as reflexões eram expressas oralmente, nos encontros semanais com os colegas e com o supervisor de estágio; em outros, elas foram registradas nos diários; outras alunas, ainda, fizeram o registro sistemático das reflexões no relatório final de estágio.

Podemos fazer um paralelo dessa realidade - as maneiras como eram feitas as reflexões - com as ideias de Yinger e Clark (1981), que afirmam que a escrita de um fato não acontece de modo mecânico e inconsciente e é um processo de criação-revisão, pois, ao ler o que escreveu, é possível ao autor avaliar esse registro, refletindo se a escrita está clara, pensando sobre os objetivos dessa escrita. Retomando Zabalza (1994, p. 95), “a descrição vê-se continuamente excedida por abordagens reflexivas sobre os porquês e as estruturas de racionalidade e justificação que fundamentam os factos narrados". Essas premissas permitem-nos inferir que o relato escrito das experiências e as reflexões sobre elas possuem uma relação estreita. 
Essa relação íntima entre escrita e reflexão pode justificar o não registro, em alguns diários, das reflexões e das análises sobre os acontecimentos: sua ausência não necessariamente significa que elas não fossem feitas - as análises estavam presentes no pensamento das graduandas e, muitas vezes, foram explicitadas nos encontros semanais com o professor supervisor de estágio e os colegas do curso; além disso, o relatório entregue ao final do estágio configurou-se como um espaço para o registro das análises realizadas ao longo do período. É importante destacar que as futuras professoras informaram que a descrição densa dos acontecimentos, com o registro na ordem de ocorrência dos fatos, permitiu reflexões mais aprofundadas.

As graduandas consideraram essa densidade das informações um aspecto fundamental para a ocorrência das análises das experiências. Como nos mostram os dados, podemos inferir que um relato superficial implicaria reflexões e análises igualmente superficiais.

Diante dessa constatação sobre a densidade da descrição dos fatos, podemos retomar a ideia de Zabalza (1994) de que, por conta de os diários serem "longitudinais e históricos", seus escritos permitem identificar e analisar o(s) pensamento(s) do professor ao longo do percurso narrado. Afinal, "o diário conserva a sequência, evolução e actualidade dos dados recolhidos" (p. 97). Percebe-se que esses aspectos - longitudinal e histórico - assinalados por Zabalza (1994) são características presentes nos diários das participantes desta pesquisa, pois elas escrevem a sequência dos acontecimentos pela proximidade destes.

\section{Contribuições da escrita de diários na formação docente}

Nos comentários sobre as contribuições da escrita de diários para a formação docente, destacam-se três aspectos: contribuição para a reflexão, contribuição como um apoio à memória, contribuição para distanciar-se dos fatos.

Sete alunas assinalaram a reflexão como um contributo dos diários. Segundo elas, a elaboração dos diários permitiu a reflexão sobre a prática observada e sobre a sua própria prática, quando ministraram as regências e/ou acompanharam os alunos nas atividades propostas pela professora. Os excertos abaixo são exemplos dessa contribuição. 
[O diário] Influenciou a mais reflexões e dados não perdidos, como no caso dos problemas e dificuldades que as crianças enfrentaram no estágio que pude de alguma forma auxiliar. [...] pude perceber como as anotações são importantes para reflexões, análises da prática pessoal e dos problemas enfrentados, podemos apontar possibilidades de caminhos. (Simone)

Ter relatado sobre a participação dos alunos perante minhas regências foi muito importante, visto que descrevi situações concretas da realidade escolar que eu não havia vivenciado. [...] A sala de aula que realizei o estágio em muitos momentos se demonstrou dispersa e indisciplinada. Alguns alunos especificos tinham comportamentos de indisciplina que desencadeavam a dispersão de toda a sala. Observava as atitudes da professora e relata as situações no diário de campo. Minhas observações e os relatos faz̧iam com que eu refletisse a respeito de como me portaria diante de situações como esta. (Rachel)

Das sete estudantes que assinalaram a como resultado da escrita dos diários, três alunas afirmaram que a reflexão é potencializada por outra contribuição dos diários: servir como um apoio à memória das estagiárias. Como nos mostra a afirmação de Fernanda:

Os diários me ajudaram a refletir mais sobre a prática e me manter atenta a pequenos detathes que ocorrem na sala de aula. Ajuda a recordar nossa prática e com certeza isso reflete na sala de aula [...] os diários também contribuem para eu relembrar algumas atividades dadas em sala de aula e que hoje as utilizo para aplicar, por exemplo, nas nossas insercoôes da disciplina de Problemas de ensino e de aprendizagem. (Fernanda)

Também de acordo com Simone, os diários foram um apoio para a memória e possibilitaram mais reflexões sobre os conflitos da prática educativa e a busca de caminhos para superar esses conflitos.

Maria, da mesma forma, considerou importante a escrita dos acontecimentos vivenciados no estágio, pois o registro funcionou como apoio à memória e, desse modo, a reflexão pôde ser mais aprofundada.

Existem detalhes que muitas vezes nos passam despercebidos e estando nos diários é uma forma de reavaliar a situação e as causas de seu fim. Por exemplo, durante um dia (ou dias) determinado aluno está disperso, triste e não brinca como antes. Ele pode ter brigado com um colega, ter presenciado cenas inadequadas em casa ou na TV, ou simplesmente ter se desmotivado por algum acontecimento cotidiano da sala de aula.

Outra aluna também apontou que o diário proporciona a reflexão dos acontecimentos e acrescentou que, para ela, o distanciamento entre a leitura do diário e as experiências vividas permite a análise mais densa destas. 
[O diário apresenta] uma grande contribuição para a memória e depois, principalmente, pela oportunidade de re-vivenciar as situações e observar por um ângulo diferente. Penso que esse outro olhar é bem importante, pois me tira da situação e me faz observar melhor os detalhes. Só olhando de fora (lendo aquilo que você mesmo escreveu) você é capaz. de analisar a situação mais friamente e, dai então, resolvê-la com mais tranquilidade. Ao ler aquilo que escrevemos mudamos a nossa visão, como então uma $3^{a}$ pessoa. (Marília)

Por ter vivido a experiência de registro diário no estágio, Marília afirmou que, atualmente, tem mais cautela no momento de agir na sala de aula:

"Agora tomo muito cuidado com as coisas que falo para as crianças, tento sempre pensar antes de agir. Quando acontece algo envolvendo a professora, procuro a melhor hora e forma para conversar, procuro analisar todas as situaçôes e atitudes das crianças".

Considerando as afirmações das participantes, constatamos que a elaboração de diários contribui para a reflexão sobre aspectos vários da prática educativa: ações da professora, receptividade dos alunos às atividades propostas pela professora, ensino de conteúdos específicos, relação entre os alunos, relação professor-aluno, prática da estagiária no momento das regências. Além disso, no caso de uma aluna, foi possível constatar que essas reflexões proporcionaram mudanças de concepções e de ações pedagógicas.

Alves (2004) destaca que o diário pode converter-se em importante descoberta e desafio para o docente e para seu contexto profissional. Assinala também que os professores que elaboram diários tornam-se notoriamente mais reflexivos e autocríticos que aqueles que não o fazem. Cunha (1997) afirma que as narrativas podem provocar mudanças na forma como as pessoas compreendem a si próprias e aos outros.

Além disso, diante desses dados, ressaltamos que considerar o diário como um instrumento de auxílio à memória é um ponto positivo, pois, conforme apontam Bolívar et al., (2001 apud ALVES, 2004), o diário preserva os fatos narrados de distorções que, com o tempo, a memória pode introduzir. Desse modo, de certa forma, o registro no diário possibilita a fidedignidade dos acontecimentos analisados; por isso, ele é adequado para o registro das ações e dos pensamentos ao longo de determinado período. Contudo, é importante não negligenciar uma limitação do diário: seu autor pode escolher quais acontecimentos e pensamentos serão relatados, ou seja, alguns acontecimentos podem ficar ocultos nos regis- 
tros, pois, de acordo com Ramos e Gonçalves (1996, p. 127), "possivelmente, ele [o autor] levantará o véu apenas da parte que, de si próprio, pretende que se saiba e que venha a ser lembrado".

Outro contributo dos diários, na perspectiva de uma das participantes, é que ele proporciona o distanciamento dos fatos vivenciados, possibilitando um "novo olhar" sobre eles. Esse distanciamento é comentado por Marília, que afirma que o registro no diário permite uma análise distanciada do que foi vivenciado, e essa distância é fundamental para aprofundar suas análises.

De acordo com Zabalza (1994), a narração implica reflexão, pois, ao escrever, é possível distanciar-se e analisar as experiências relatadas a partir de outra perspectiva, ou seja, é possível dialogar consigo mesmo. Cunha (1997) também assinala esse distanciamento possibilitado pela narrativa.

A narrativa provoca mudanças na forma como as pessoas compreendem a si próprias e aos outros. Tomando-se distância do momento de sua produção, é possível, ao "ouvir a si mesmo" ou ao "ler" ser escrito, que o produtor da narrativa seja capaz, inclusive, de ir teorizando a própria experiência. Este pode ser um processo profundamente emancipatório em que o sujeito aprende a produzir sua própria formação, autodeterminando a sua trajetória. (CUNHA, 1997, p. 3)

Além do "ouvir a si mesmo", assinalamos a importância do diálogo com o outro. Sobre esse compartilhamento, Bolívar et al. (2001 apud ALVES, 2004, p. 238) destacam que o diário deve ser compartilhado e analisado por todos:

Se queremos que o diário não fique reduzido a um espaço de auto-reflexão privada e intimista, o mesmo deve ser exposto e analisado com o grupo de pares, com o assessor, com o facilitador ou investigador. Deste modo, pode converter-se num instrumento para a reflexão, análise e autoavaliação.

Amaral, Moreira e Ribeiro (1996) também apontam que as narrativas escritas pelos estagiários devem ser compartilhadas com os colegas de estágio, pois a discussão e a reflexão sobre as experiências vividas podem ser contributos para a aprendizagem da docência.

Por fim, verificamos que duas alunas afirmaram que a escrita dos diários, no decorrer do estágio, não contribuiu de modo efetivo para sua 
formação. Carol revelou que os diários possibilitaram a reflexão, mas não trouxeram grandes contribuições para sua formação, pois considera que as análises que fez durante o estágio foram de utilidade imediata. Podemos inferir que a aluna não percebeu que as reflexões que aparentemente se referem a casos específicos podem ser aplicadas a outros casos mais gerais. Um caso específico pode possibilitar a adição de ideias novas ao repertório de conhecimento docente, e isso pode permitir as conexões entre ideias específicas e princípios mais gerais e possibilitar que se parta de algo particular para uma regra mais geral e vice-versa.

Também o discurso de Cris demonstra que os diários não tiveram muitas contribuições para sua formação, uma vez que os fazia de forma rápida, mais para cumprir prazos e não ficar sem nota na atividade. "Confesso que não explorei a potencialidade reflexiva dos diários. Eles foram bem mais tarefas para obtenção de nota do que um momento de reflexa".

Essa dificuldade de escrever relacionada à falta de tempo também foi constatada nas pesquisas de Ferreira (2005) e Corsi (2002). Ferreira (2005) aponta que o tempo para escrever os diários foi um aspecto ressaltado pelos sujeitos de sua pesquisa que, muitas vezes, escreveram os diários quando estavam cansados. Isso pode ter proporcionado a realização de escritas mais descritivas do que reflexivas. Corsi (2002) destaca que as dificuldades que o professor pode encontrar ao elaborar os diários reflexivos podem ser devidas a falta de tempo, de hábito ou podem, ainda, ser motivadas por não perceberem sua utilidade.

Podemos retomar as ideias de Zabalza (1994), que afirma ser o diário um recurso penoso: é difícil escrever após um dia de trabalho e em meio às tarefas cotidianas. Porém, assinala que, mesmo sendo um processo penoso, é prazeroso, pois, ao escrever o diário, o professor encontra sentido e utilidade na escrita.

\section{Implicações para a formação docente}

Tendo em vista as discussões realizadas até o momento, refletiremos agora sobre algumas das implicações dos dados para a formação docente: a necessidade de o supervisor de estágio oferecer feedbacks diante dos acontecimentos, dos sentimentos, das perspectivas e das opiniões relatadas; e a importância de as reflexões estarem baseadas em estudos teóricos. 
A primeira implicação refere-se ao apontamento de algumas estudantes, que indicaram que o feedback do supervisor de estágio é importante para o uso eficaz dos diários como ferramenta formativa. Quatro alunas mostraram o papel do supervisor de estágio ao fornecer feedbacks escritos ou orais diante dos relatos das experiências vividas.

De acordo com Carol, os feedbacks da supervisora de estágio permitiram pensar na elaboração de estratégias a serem realizadas nas próximas aulas de estágio e serviram para melhorar a escrita dos diários.

Na perspectiva de Simone, os feedbacks possibilitaram que atentasse de forma reflexiva para ações, falas, fatos que não havia percebido no decorrer do estágio e durante o registro dos diários.

Além disso, as participantes desta pesquisa mostraram que a discussão sobre as experiências de estágio com o formador e os colegas nos encontros semanais na universidade também foram fundamentais para estimular a reflexibilidade.

Raquel assinala as contribuições dessas discussões orais sobre os relatos apresentados nos diários. Estes permitiram que relatasse à sua supervisora e aos colegas as "experiências e situações concretas da sala de aula, fato que desencadeou discussões teóricas e reflexivas".

Marília também apresenta uma perspectiva semelhante à dessas alunas. De acordo com ela:

[...] a supervisora dava notas, mas, além disso, ela fazia comentários no Moodle e na sala baseando-nos teoricamente; como futura professora sinto que avancei muito na questão dos diários e acredito nos diários como meio de formação constante.

[...] mas nada como a opinião dos colegas, por terem outra visão sobre o assunto, da supervisora, por todo aparato teórico e prático de anos de experiência e estudo e da mestranda (ou doutoranda, não me lembro...) que nos acompanhava, tanto pela visão diferente, como pelo aparato teórico que ela carregava.

Tendo por base os dados apresentados, destacamos que o supervisor de estágio tem papel fundamental no acompanhamento dos diários, pois alguns dados revelam que pode não ser suficiente propor essa atividade, isto é, simplesmente solicitar que os graduandos registrem os acontecimentos do dia de estágio, sem oferecer um retorno efetivo desses registros. Isso parece não ser condição suficiente para potencializar a análise das experiências vividas. Assinalamos que, por meio dos registros das 
futuras professoras, o formador pode ter ciência das experiências que elas vivenciam, dos sentimentos, dos dilemas e das opiniões; e, a partir desses elementos, propor questionamentos, interpretações e perspectivas que proporcionem a reflexão e a análise dos fatos vivenciados pelos graduandos. De acordo com as perspectivas das participantes desta pesquisa, os feedbacks aos diários podem ocorrer na forma escrita ou oral. Nesse cenário, discutiremos o conceito de supervisão segundo Alarcão, Tavares (1987), Blumberg (1980) e Alarcão (2001a; 2001b).

Para Alarcão e Tavares (1987), a ideia de supervisão não se relaciona com controle ou com vigilância, mas com a orientação da prática pedagógica, e objetiva o desenvolvimento profissional docente. Segundo esses autores, o supervisor deverá propiciar a aprendizagem do professor e poderá fazer isso de diferentes maneiras: "através da demonstração, da reflexão, da apresentação de modelos, da análise de conceitos, da exploração de atitudes e sentimentos, da análise de modelos, de jogos de simulação, de problemas a resolver, de tarefas a executar etc.” (p. 44). O supervisor não oferecerá respostas prontas e, em alguns casos, será necessário que desenvolva uma orientação mais direta; ou seja, precisará oferecer informações e estratégias que mostrem o que o estagiário ou o professor pode fazer. Contudo, a finalidade do supervisor é trabalhar junto com o professor em formação; afinal, é fundamental que o futuro docente desenvolva a reflexão, atitudes de determinação, responsabilidade e iniciativa.

Blumberg (1980) preconiza que o conceito de supervisão tem o objetivo de orientar o professor, e não o de avaliá-lo. Ou seja, esse tipo de supervisão foca uma intervenção deliberada, considerando as demandas do professor (demandas individuais e coletivas), e exige confiança mútua, apoio e compreensão. A sala de aula, isto é, casos reais de ensino e aprendizagem, é o ponto de partida para a análise, pelo professor e supervisor, da prática docente. Em seu estudo, o autor discute diferentes percepções dos professores sobre a ideia de supervisão e a interação deles com os supervisores e considera inviável que o supervisor estabeleça uma relação artificial e distante do professor, permeada por tensões e inibições.

Nesse cenário, Blumberg (1980) identificou diferentes tipos de supervisão e aponta quatro tipos de relações que podem ocorrer entre supervisor e professor: (1) relação muito direta e muito indireta, na qual o supervisor expõe suas ideias e perspectivas, mas também faz perguntas e 
ouve o professor; (2) relação muito direta e pouco indireta: o supervisor ouve pouco o professor e prioriza a exposição de suas próprias ideias; (3) relação pouco direta e muito indireta, na qual o supervisor ouve o professor, questiona-o, valoriza suas ideias, mas não expõe suas próprias perspectivas; (4) relação pouco direta e pouco indireta: neste caso, o supervisor tem papel passivo.

Os estudos desse autor indicam que os professores não têm uma perspectiva positiva em relação aos supervisores de atitude passiva ou aos que falam muito; por outro lado, consideram positivos os supervisores que expõem suas ideias, fazem sugestões, criticam, comentam e solicitam do professor informações e opiniões.

Baseando-se nesses estudos, Alarcão e Tavares (1987) assinalam que estratégias de colaboração devem ser privilegiadas pelos supervisores, porém isso não significa que elas sejam adequadas a todos os casos. Especificamente no caso dos futuros professores e no dos docentes iniciantes, os autores alertam que, por causa da falta de experiência, às vezes, eles precisam de uma orientação mais direcionada. Além disso, o tipo de supervisão também pode variar, tendo em vista o nível de desenvolvimento cognitivo e afetivo do professor e do supervisor. Diante das considerações expostas, é necessário assinalar que, tradicionalmente, na literatura, o conceito é relativo ao docente (mais especificamente ao futuro professor) e sua atuação na sala de aula (ALARCÃO, 2001a). Contudo, a autora alerta para uma ampliação desse conceito ao ressaltar que o objetivo da supervisão deve ir além da melhoria da qualidade na sala de aula, mas considerar a escola como um todo, visando "ao desenvolvimento qualitativo da organização escolar e dos que nela realizam o seu trabalho de estudar, ensinar ou apoiar a função educativa através de acções individuais e colectivas, incluindo a formação de novos agentes” (p. 18). Nesse sentido, o supervisor assume o papel de líder ou facilitador e deve saber relacionar reflexão, planejamento, avaliação e ação.

Nessa perspectiva, o supervisor não atua como um fiscalizador, mas tem papel de apoio, colaborando no projeto de desenvolvimento da escola e do currículo, assim como no processo de autoavaliação da instituição e de avaliação dos funcionários, dos processos educativos e resultados de aprendizagem, entre outros ${ }^{3}$.

De acordo com Alarcão (2001b), no Brasil na década de 1970, o conceito de supervisão esteve influenciado por ideias tecnocráticas. O 
supervisor era, portanto, o instrumento para executar políticas e verificar a implantação delas. Contudo, ao longo dos anos, o conceito de supervisão adquire um viés pedagógico, dirigindo-se ao ensino e à aprendizagem, sendo que os critérios e a apreciação da qualidade do ensino não são impostos, mas construídos e dialogados entre supervisor e professor. Assim, "ao superpoder orientador e controlador contrapõe-se uma concepção mais pedagógica da supervisão concebida como uma co-construção, como os professores do trabalho diário de todos na escola" (ALARCÃO, 2001b, p. 12), sendo que o supervisor representa uma leitura global dessa instituição. Entretanto, ainda segundo a autora, esse discurso, no Brasil, não é acompanhado por sua concretização. A figura do supervisor como inspetor, controlador e sujeito externo à escola ainda é presente.

Consideramos que as premissas expostas possam contribuir para discutirmos o apontamento das participantes da pesquisa sobre a necessidade de o supervisor de estágio oferecer feedbacks dos diários.

A pesquisa de Galiazzi e Lindemann (2003) apresenta-nos uma maneira de utilizar os diários como ferramenta formativa, em que o diálogo entre futuro professor e formador adquire papel de destaque. As autoras mostram os tipos de feedbacks da supervisora de estágio: questionamentos sobre as opiniões e os valores apresentados pela estagiária diante de determinado fato observado; comentários, sugestões e estímulos ao trabalho desenvolvido pela estagiária; questionamentos e apontamentos sobre os saberes que a estagiária apresentava sobre o currículo, as estratégias de ensino, os alunos, os conhecimentos atitudinais, entre outros.

De acordo com as autoras, esses feedbacks transformaram o diário em um instrumento de diálogo, proporcionando o desenvolvimento de um professor reflexivo, com conhecimentos mais fundamentados "pelo diálogo consigo mesmo e com seus professores" (GALIAZZI; LINDEMANN, 2003, p. 149). Além disso,

A reflexão dos envolvidos favoreceu a construção de conhecimento profissional mais complexo, o que nos faz propor sua utilização como forma de intensificar o diálogo entre os formadores e alunos; de ampliar o conhecimento dos formadores sobre a escola; de tornar a vivência do estágio um movimento do estagiário e dos professores de explicitar suas teorias curriculares e, pelo diálogo, enriquecê-las. 
Constata-se que há vários tipos de feedbacks a serem desenvolvidos e que cada um não pode ser encontrado em forma única. Nesse cenário, corroboramos a ideia de Ramos e Gonçalves (1996, p. 141) segundo quem os supervisores devem auxiliar os futuros professores a analisar os conteúdos expostos nos diários "de modo explanatório e retrospectivo e, se possível, a pôr os seus textos em confronto com outras histórias de vida".

Portanto, podemos levantar a hipótese de que a escrita do diário por si só possa não propiciar a reflexão e a análise dos fatos vivenciados no estágio dos futuros professores, sendo fundamental a concretização de um diálogo com agentes externos, que podem ser o professor formador e os colegas de estágio.

Outra implicação para a formação docente alude à questão de que a reflexão dos acontecimentos é embasada pela realização de estudos teóricos. Lara afirmou que "para fazer a reflexão en precisava estar com os textos da matéria em dia e, depois disso, eu relia os diários de observação e a então começava a escrever a reflexão". Francisco assinalou que "o processo de construção do diário se estabelecia com o regaste de alguns elementos já vivenciados durante o curso". Marília apontou que "[os referenciais teóricos] ajudavam bastante ao fazer as reflexões”. As considerações dessas três alunas mostram que as reflexões realizadas sobre o estágio tendo por base os registros dos diários não eram feitas em um vazio teórico.

Segundo Pimenta (2006), a teoria representa uma atividade de conhecimento e teleológica, ou seja, implica conhecer a realidade presente e prefigurar finalidades para transformá-la. Ressalta-se que a atividade de conhecer e a teleológica são atividades teóricas, pois, por si sós, não proporcionam a transformação da realidade, não materializam as finalidades, não são uma práxis. Sendo assim, por meio da teoria, o futuro professor pode conhecer a realidade e preconizar finalidades para modificála, estabelecendo planos de ação, objetivando a aprendizagem dos alunos.

No caso das estagiárias, o saber teórico foi mobilizado ao vivenciarem a prática pedagógica, possibilitando que suas análises não recaíssem em um praticismo ou em um tecnicismo simplista, indo além da ênfase nos aspectos técnicos do ensino e dos acontecimentos da sala de aula. Nesse caso, o licenciando pode desenvolver-se como um docente que não aplica, simplesmente, sem uma análise crítica, as teorias aprendidas na universidade; que não negligencia outros aspectos da educação, como as 
dimensões éticas e morais; e que, ao refletir sobre os alunos e seu ensino, não desconsidera o contexto social e institucional que influencia a prática escolar.

\section{Algumas considerações}

O presente estudo buscou investigar, na perspectiva das alunas de um curso de Pedagogia, as contribuições da escrita de diários de campo para sua formação docente. Ao longo deste texto, discutimos que o diário pode ser um instrumento formativo que possibilita a análise das experiências vividas no cotidiano escolar.

As participantes da pesquisa apontaram que elaboravam o diário logo que chegavam em casa após o estágio, pois, dessa forma, poderiam evitar esquecer detalhes observados. Também faziam uma descrição detalhada dos fatos, de acordo com a sequência de ocorrência destes, o que permitiu reflexões mais aprofundadas. Constatamos também que a maioria das participantes destacou que a elaboração dos diários permite a reflexão sobre a prática observada e sobre a sua própria prática, quando elas ministraram as regências e/ou acompanharam os alunos nas atividades propostas pela professora. Para algumas, além de possibilitar a reflexão, o diário oferece um apoio à memória, sendo esse aspecto fundamental para o registro real e denso dos acontecimentos. Ainda, verificamos que, na perspectiva das participantes, o diário possibilita o distanciamento das experiências vividas, permitindo sua análise mais profunda.

Questionamos quais as implicações desses dados para a formação docente e elencamos duas: a necessidade de o supervisor de estágio oferecer feedbacks, orais ou escritos, dos acontecimentos, dos sentimentos, das perspectivas e das opiniões relatadas; e a importância de as reflexões estarem baseadas em estudos teóricos.

Consideramos que o supervisor de estágio tem papel fundamental no acompanhamento dos diários, porque apenas solicitar que os estudantes registrem os acontecimentos observados no estágio e não oferecer feedback (escrito ou oral) desses registros parece não ser condição suficiente para potencializar a reflexão e a análise dos fatos. O feedback pode propiciar a apresentação de questionamentos, interpretações e perspectivas que proporcionem a reflexão e a análise dos fatos vivenciados. 
Contudo, ressaltamos que a escrita possui algumas potencialidades que talvez a discussão oral não possua: permite maior privacidade, e assuntos delicados podem ser abordados mais abertamente; responder aos feedbacks escritos pode propiciar registros com reflexões mais cuidadosas e direcionadas às demandas, pois a escrita possibilita um pensar mais cuidadoso e a revisão do que se escreveu. Além disso, assinalamos que o diálogo estabelecido com o formador permitirá que os alunos encontrem o sentido e a utilidade dos diários, aspectos que Zabalza (1994) aponta como fundamentais para se contrapor ao processo exigente e penoso da escrita.

Além disso, conforme mencionamos anteriormente, é importante que as reflexões dos estagiários se relacionem com os estudos teóricos realizados ao longo do curso. Fazer essa afirmação não significa considerar que a teoria seja um conhecimento onipotente e que a prática se limite à aplicação e/ou à degradação da teoria. A ideia que apontamos é de que o futuro professor pode articular o conhecimento especializado de que se apropria à prática pedagógica vivenciada no estágio, no sentido de que o estagiário deve aprender o saber fazer, o como fazer e o saber por que fazer, indo além do praticismo. 


\section{Referências}

ALARCÃO, Isabel (Org.). Escola reflexiva e supervisão: uma escola em desenvolvimento e aprendizagem. Porto: Porto Editora, 2001a.

ALARCÃO, Isabel. Do olhar supervisivo ao olhar sobre a supervisão. In: RANGEL, Mary (Org.). Supervisão pedagógica: princípios e práticas. Campinas, SP: Papirus, 2001b. p. 11-55.

ALARCÃO, Isabel; TAVARES, José. Supervisão da prática pedagógica: uma perspectiva de desenvolvimento e aprendizagem. Coimbra: Almedina, 1987.

ALVES, Francisco Cordeiro. Diário: contributo para o desenvolvimento profissional dos professores e estudo dos seus dilemas. Millenium: Revista do ISPV, [S.1.], n. 29, p. 222-239, dez. 2004. Disponível em <http://www.ipv.pt/millenium/Millenium29/30.pdf>. Acesso em: 14 set. 2009.

AMARAL, Maria João; MOREIRA, Maria Alfredo; RIBEIRO, Deolinda. O papel do supervisor no desenvolvimento do professor reflexivo: estratégias de supervisão. In: ALARCÃO, Isabel (Org.). Formação reflexiva de professores: estratégias de supervisão. Portugal: Porto Editora, 1996. p. 89-124.

BLUMBERG, Arthur. Supervision and teachers: a private cold war. California: McCutchan, 1980.

CATANI, Denice B.; BUENO, Belmira O.; SOUSA, Cynthia P.; SOUZA, Maria Cecília C. Docência, Memória e Gênero: estudos sobre formação. São Paulo: Escrituras, 2000.

CORSI, Adriana Maria. O início da construção da profissão docente: analisando dificuldades enfrentadas por professoras de séries iniciais. 2002. 163f. Dissertação (Mestrado em Educação) - Centro de Educação e Ciências Humanas, Universidade Federal de São Carlos, São Carlos, 2002.

CUNHA, Maria Isabel da. Conta-me agora!: as narrativas como alternativas na pesquisa e no ensino. Revista da Faculdade de Educação, [S.1], v. 23, n. 1-2, 1997. Disponível em: <http: / / www.scielo.br/scielo.php?script=sci_arttext\&pid=S010225551997000100010\#1aut>. Acesso em: 20 maio 2008.

FERREIRA, Lilian Aparecida. O professor de educação física no primeiro ano da carreira: análise da aprendizagem profissional a partir da promoção de um programa de iniciação à docência. 2005. 250f. Tese (Doutorado em Educação) - Centro de Educação e Ciências Humanas, Universidade Federal de São Carlos, São Carlos, 2006.

GALIAZZI, Maria do Carmo; LINDEMANN, Renata Hemandez. O diário de estágio: da reflexão pela escrita para a aprendizagem sobre ser professor. Olhar de professor, [S.l], v. 6, n. 1, p. 135-150, 2003.

LAMPERT, Magdalene. Learning teaching in, from, and for practice: what do we mean? Journal of Teacher Education, [S.1], v. 61, n. 1-2, p. 21-34, 2010.

MALERBA, Jurandir. Pensar o acontecimento. História Revista, [S.1.], v. 7, n. 1-2, p. 117149, 2002. Disponível em:

$<$ http://www.revistas.ufg.br/index.php/historia/article/download/10489

/6968>. Acesso: jun. 2011.

MEDEIROS, Dalva H.; PÁTARO, Cristina S. O. O diário de estágio na formação inicial de professores: possibilidade de reflexão e articulação teoria e prática. In: CONGRESSO DE LEITURA DO BRASIL, 17, 2009, Campinas-SP. Anais... Campinas: COLE, 
2009. p. 1-11.

MIZUKAMI, M. G. N., REALI, A. M. M. R., REYES, C. R., MARTUCCI, E. M., LIMA, E. F., TANCREDI, R. M. S., MELLO, R. R. Escola e aprendizagem da docência: processos de investigação e formação. São Carlos: EdUFSCar, 2003.

PIMENTA, Selma Garrido. O estágio supervisionado na formação de professores: unidade teoria e prática? São Paulo: Cortez, 2006.

RAMOS, Maria Antonia; GONÇALVES, Rosa Edite. As narrativas autobiográficas do professor como estratégia de desenvolvimento e a prática da supervisão. In: ALARCÃO, Isabel (Org.). Formação reflexiva de professores: estratégias de supervisão. Portugal: Porto Editora, 1996. p. 123-150.

SILVA, Maria H. S., DUARTE, Maria C. O diário de aula na formação de professores reflexivos: resultados de uma experiência com professores estagiários de biologia/geologia. Revista Brasileira de Pesquisa em Educação em Ciências, [S.1.], v. 1, n. 1-2, p. 73-84, 2001.

SOUZA, Elizeu C.; CORDEIRO, Verbena M. R. Por entre escritas, diários e registros de formação. Presente! Revista de Educação, [S.1], n. 57, jun., p. 45-49, 2007.

YINGER, Robert J.; CLARK, Christopher M. Reflective Journal Writing: theory and practice. Paper. (occasional serie, n. 50), IRT, Michigan State Univ., East Lansing, Michigan. 1981.

ZABALZA, Miguel A. Diários de aula: contributo para o estudo dos dilemas práticos dos professores. Porto: Porto Editora, 1994. 


\section{Notas}

1 Zabalza (1994, p. 108) conceitua o dilema como "todo o conjunto de aspectos que o professor apresenta como problemáticos e que constituem para ele um foco constante de preocupação, incertezas e reflexões".

2 É importante destacar que, com base nos dados dos questionários não é possível identificar os tipos de reflexões realizados; por isso, consideramos que o termo "reflexão" pode ter sido utilizado pelos alunos com um sentido de "pensar sobre as experiências". 3 Além de assinalar as características do supervisor, podemos destacar que, embora haja investimentos em políticas públicas de formação de professores, observa-se que a ênfase tem sido dada a professores da educação básica. A formação do professor universitário, nela incluídos o professor das licenciaturas e o supervisor de estágio, é tema ainda pouco frequente na definição do que devem saber e ser capazes de ensinar. Entende-se, porém, que formadores de professores aprendam também a ser professores, como os demais, e uma das fontes de aprendizagem mais relevantes é o próprio ensino, que, de acordo com Lampert (2010), implica uma ação concertada entre formadores e os futuros professores que envolve colaboração intelectual e social em que ambos aprendem. Implica ainda, da parte dos formadores, o estabelecimento de uma relação com o conteúdo específico que os estudantes devem aprender. Este é um processo complexo, pois exige do formador compreender o conteúdo específico, planejar suas ações ou aulas, representá-lo, demonstrá-lo e explicá-lo. Tais relações ocorrem ao longo do tempo e envolvem arranjos interpessoais, e os problemas de ensino decorrentes das relações estudantes e conteúdo são minimizados em momentos específicos de interação. São construídas diferentemente, tendo em vista os diversos estudantes e grupos de estudantes. Cada tipo de relação social entre os formadores e os estudantes (pares, grupo e classes) simultaneamente envolve conteúdos intelectuais e desafios interpessoais diferentes. Por isso, defende-se que disponham de espaços e tempos que favoreçam o desenvolvimento profissional. 
